\title{
Primary coronary angioplasty in acute myocardial infarction
}

\author{
Ever D Grech, David R Ramsdale
}

\begin{abstract}
Summary
It is well established that recanalisation of the infarct-related artery is of great benefit in the early hours after acute myocardial infarction. This can be achieved by the use of thrombolytic agents and/or by percutaneous transluminal coronary angioplasty (PTCA). This article reviews data on the role of primary PTCA and summarises current opinion on its use.
\end{abstract}

Keywords: percutaneous transluminal coronary angioplasty, myocardial infarction

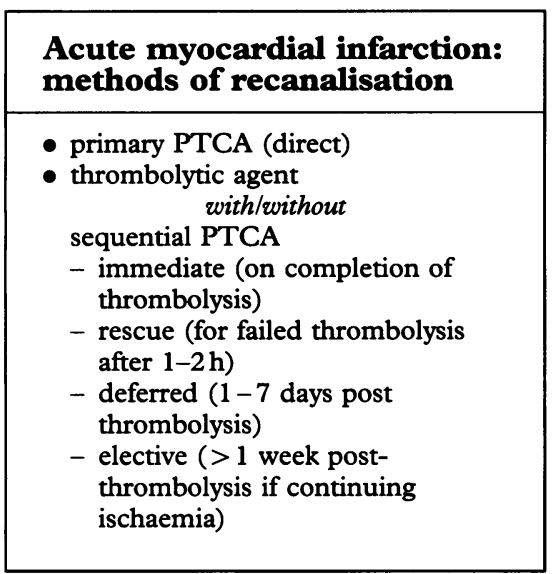

Box 1

The Cardiothoracic Centre, Thomas Drive, Liverpool L14 3PE, UK ED Grech DR Ramsdale
In 1980, De Wood et al first reported angiographic evidence of a high incidence of totally occluded or critically stenosed infarct-related arteries in the early hours of acute myocardial infarction. ${ }^{1}$ Such findings prompted the use of intracoronary and later intravenous streptokinase therapy. It is now well established that after acute myocardial infarction, the earlier the infarct-related artery is recanalised, the greater the benefits to the patient - both in terms of reduced infarct size and improved survival. ${ }^{2}$

There are presently two methods of achieving recanalisation of the infarctrelated artery. The first is the intravenous administration of a thrombolytic agent, resulting in the enzymatic degradation of the occlusive thrombus. The second is primary (or direct) percutaneous transluminal coronary angioplasty (PTCA). This contrasts with sequential PTCA, which may be performed at various times after thrombolytic therapy has been administered (box 1). After the promising results of early thrombolytic trials, there was considerable interest in sequential PTCA. It was observed that following successful thrombolytic recanalisation, a high-grade residual lesion was frequently observed and led Meyer et al to use PTCA after intracoronary streptokinase during the same sitting. ${ }^{3}$ This combination treatment was advocated as a means of avoiding reocclusion and recurrent ischaemia. The rationale for dealing with the flowlimiting potential of the residual plaque has led to many studies which have examined the need to proceed to PTCA at various times but there continue to be unresolved issues about optimal strategies for sequential PTCA and doubts about its efficacy. Results of the major randomised trials involving sequential PTCA have been reviewed elsewhere. ${ }^{4}$ However, primary PTCA may offer patients a better alternative to thrombolytic therapy, providing a superior mode of recanalisation.

The technique of coronary artery recanalisation by primary PTCA was introduced in 1983 by Hartzler $e t a \bar{P}$ and its potential advantages over thrombolytic therapy were recognised even in the early experience. ${ }^{5,6}$ Primary PTCA causes mechanical disruption of the occlusive thrombus and the underlying stenosis and results in a rapid restoration of coronary blood flow. Three years ago, three prospective randomised studies from The Netherlands ${ }^{7}$ and the US ${ }^{8,9}$ compared primary PTCA with intravenous streptokinase or tissue plasminogen activator (tPA). PTCA resulted in higher patency rates (93$98 \%$ ), improved left ventricular ejection fractions, ${ }^{7}$ fewer bleeding complications and less recurrent myocardial ischaemia and re-infarction, than thrombolysis. A few centres in the US and Europe perform this technique routinely, but for logistic reasons it is uncommon practice in the UK.

\section{Advantages of primary PTCA}

Primary PTCA using a guidewire and balloon catheter has several advantages over conventional thrombolytic therapy (box 2). First, patency rates over $90 \%$ are obtained ${ }^{10,11}$ and TIMI grade III flow can be established in $95 \%$ of patients within two hours of hospital admission. ${ }^{12}$ Our experiences have supported these findings. This is significantly greater than the optimal patency rate of $55 \%$ with intravenous streptokinase, the commonest thrombolytic agent in use in the UK. ${ }^{13}$ Restoration of antegrade coronary blood flow and normalisation of the electrocardiogram is not only more rapid but is also more predictable. The more rapid and greater success is due to dislodgement and mechanical disruption of thrombus as well as the reduction of the residual atheromatous stenosis, hence reducing the risks of recurrent ischaemia, reocclusion and reinfarction. ${ }^{14}$

More important than patency rate alone is coronary artery blood flow. In their prospective, randomised, multicentre study involving 395 patients, Grines et al not only achieved a patency rate of $99 \%$ with primary PTCA, but also achieved a TIMI grade III flow in $95 \% .{ }^{8}$ In contrast, the GUSTO study patency 
Figure 1 (Left) Angiographic appearance of a totally occluded right coronary artery in a 64-year-old woman with a 2-hour history of acute inferior myocardial infarction and (right) the same artery following primary PTCA recanalisation. Note that the residual plaque-related stenosis has been alleviated, resulted in a widely patent artery and brisk antegrade flow
Figure 2 (Left) Left coronary arteriogram in a 49-year-old woman with a 90-minute history of acute anterior myocardial infarction and hypotension. The proximal left anterior descending artery is totally occluded. (Right) Following re-opening of the left anterior descending artery by primary PTCA there was a dramatic haemodynamic improvement in left ventricular function
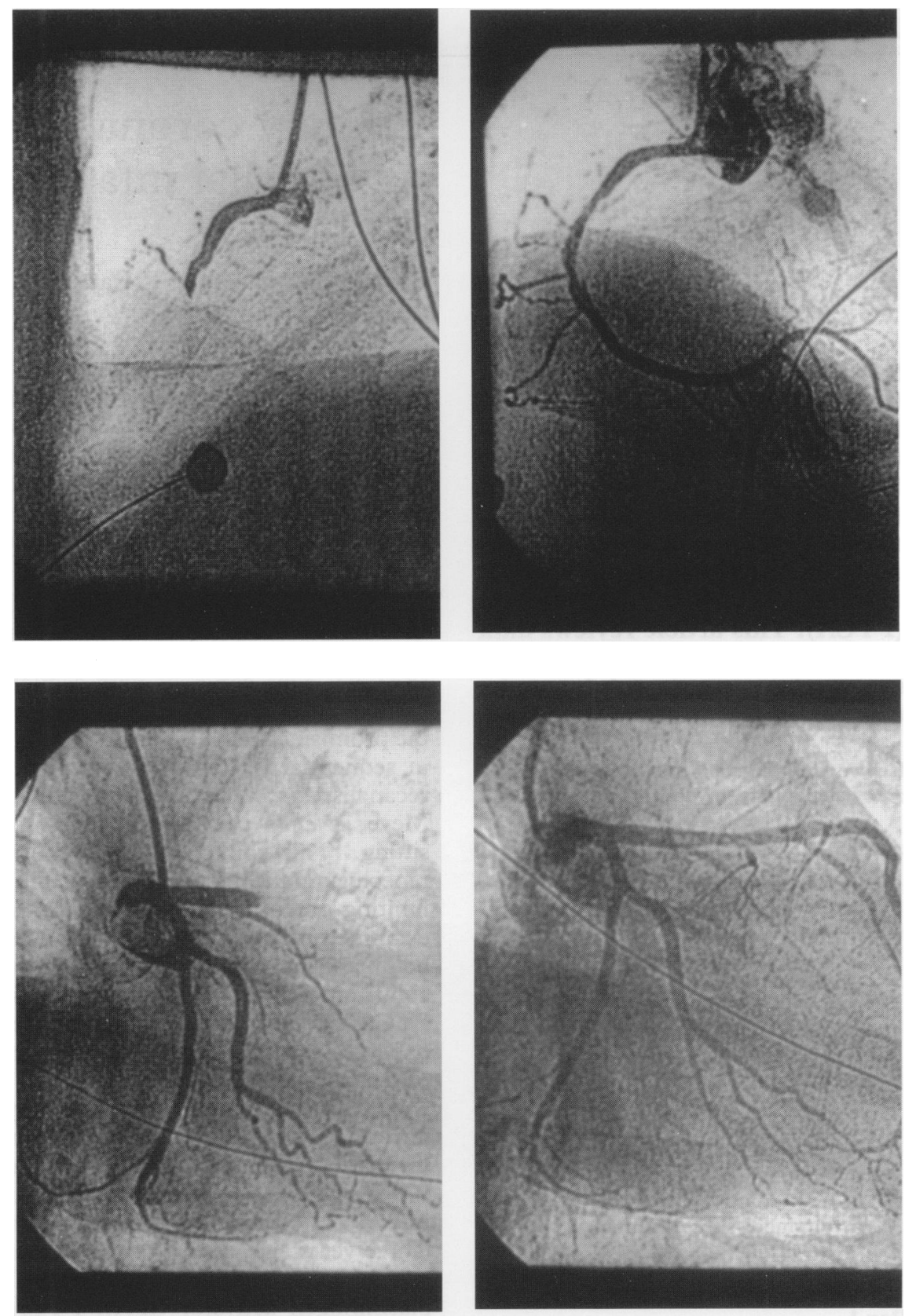

rate was $81 \%$ in the front-loaded tPA arm, although TIMI grade III flow was achieved in only $54 \% .{ }^{15}$ Furthermore, the GUSTO angiographic substudy demonstrated that in-hospital survival was directly related to the ability to achieve a patent infarct-related vessel with TIMI grade III flow. ${ }^{16}$ Figures $1-3$ are examples of the excellent angiographic result that is frequently achieved by primary PTCA within minutes of entering the catheter suite.

Since systemic fibrinolysis is avoided, the likelihood of bleeding complications as well as intra-plaque and intra-myocardial haemorrhage is reduced. ${ }^{17,18}$ If necessary, residual intracoronary thrombus can be simultaneously and effectively treated with small doses of clot-specific thrombolytic drugs administered directly down the relevant vessel. Primary PTCA can also be performed successfully when thrombolytic therapy is contraindicated due to a high risk of bleeding or an adverse haemodynamic state such as cardiogenic shock. ${ }^{19,20}$ It is probably the treatment of choice for achieving rapid reperfusion in such high-risk subsets. ${ }^{21}$

Primary PTCA leads to a reduction in infarct size and improved left ventricular function when compared to streptokinase therapy, with the most pronounced benefits in those with anterior myocardial infarction presenting within two hours after the onset of symptoms. ${ }^{22}$ These impressive results are presumably due to a rapid and effective restoration of blood flow to jeopardised myocardium. In addition to less frequent recurrent myocardial ischaemia and 
Figure 3 (Left) Angiographic appearance of a totally occluded left circumflex artery in a 69-year-old man with a 3-hour history of acute inferolateral myocardial infarction and (right) following successful primary PTCA recanalisation showing a large and dominant distal vessel


reinfarction, the need for early additional revascularisation and in-hospital mortality is less than in patients treated with intravenous thrombolytic therapy. Brodie et al have shown that after primary PTCA, patency of the infarct-related artery is the most important determinant of hospital survival and that left ventricular function measured after recovery is the most important determinant of late cardiac survival. ${ }^{23}$ The beneficial effects of primary PTCA have also been shown to be sustained up to 36 months after discharge $e^{22,24}$ although as many as $28 \%$ may require a repeat PTCA for restenosis.

Concern about the potential increased cost of primary PTCA has been examined by two studies ${ }^{9,25}$ which have found that although the expense involved in the interventional equipment was considerably greater than thrombolytic therapy, this was offset by a significantly shorter in-hospital period, fewer re-admissions and reduced follow-up costs. Both these studies were carried out in the US and used tPA which is much more expensive than streptokinase. It was argued that, in the UK, where streptokinase is the commonest thrombolytic agent in use, this would negate the reduction in overall cost attributed to PTCA. However, in a recent study from The Netherlands using intravenous streptokinase, a comparable cost difference was observed. ${ }^{22}$ They concluded that additional cost savings in primary PTCA patients could be expected during longer term follow-up.

Over and above these benefits the necessary immediate coronary angiography provides crucial information for treatment stratification. Those patients with significant left main coronary artery stenosis, severe three-vessel coronary artery disease or occluded vessels unsuitable for PTCA can be referred for by-pass surgery. Conversely, those with a patent or insignificant infarct-related vessel may be selected for medical treatment rather than unnecessary thrombolytic therapy.

\section{Disadvantages of primary PTCA}

Although there are overwhelming advantages to primary PTCA, there are also drawbacks (box 3). Some are consequent to the nature of the procedure

\section{Disadvantages of primary PTCA}

- can only be performed when cardiac catheterisation facilities, experienced staff and surgical cover available

- high capital and running cost of catheter lab

- risks/complications of catheterisation and PTCA present

- reperfusion arrhythmias common (may be due to more rapid recanalisation)

- primary PTCA more rapid than thrombolysis only if $24 \mathrm{~h}$ on-call team available 
whilst others are major resource and manpower issues. Clearly, the procedure can only be performed when cardiac catheterisation facilities, staff, and experienced operators are available. Cardiac catheter facilities require a high initial capital expenditure as well as generating significant running costs. A 24-hour on-call team and an open, available laboratory are necessary if coronary recanalisation by PTCA is to be more rapid than by thrombolysis. Herein lie the major logistical difficulties in the UK. In our centre, where catheter laboratory staff are on call from home, the average time from admission to re-opening of the infarct-related artery by PTCA may be in the order of 60 minutes.

Complications include those of cardiac catheterisation and PTCA which are slightly more frequent than after elective PTCA for chronic angina. Procedures can be simple and short in duration ( $<20 \mathrm{~min}$ ) or complex and prolonged affairs ( $>2$ hours). Ventricular arrhythmias not uncommonly occur shortly after reperfusion, although these can be promptly treated. Right coronary artery procedures are more often troublesome than those in the left and are more often associated with sinus arrest, atrioventricular block, idioventricular rhythm and severe hypotension. ${ }^{26,27}$ Primary PTCA, like elective PTCA, is associated with operator-dependent morbidity and mortality that varies with the skill and experience of the interventional cardiologist. ${ }^{22,28}$ It should only be considered in patients presenting early and when an experienced angioplasty team is available. Cardiac surgical back-up is essential and mechanical support techniques such as intra-aortic balloon counterpulsation should be available for use if risks are to be minimised.

\section{Is patient selection essential?}

Unless cases are carefully selected, many patients who are unsuitable for PTCA may undergo angiography. However, this does not preclude them from receiving thrombolytic therapy as an alternative and angiography may help improve their risk stratification and identify appropriate patients who require emergency coronary artery by-pass surgery.

Although not contraindicated, patients with previous myocardial infarction(s), a long history of angina, previous coronary artery by-pass grafting and proven multi-vessel or diffuse coronary disease, are often technically unattractive prospects for primary PTCA. However, even here direct PTCA may be shown to have a greater benefit than thrombolytic therapy if undue time delays to treatment can be avoided. Primary PTCA offers a clear additional benefit over thrombolytic therapy in elderly patients ( $>65$ years), who may be at greater risk from the effects of recurrent ischaemia and re-infarction. ${ }^{29}$ Moreover, the increased haemorrhagic complications (in particular intracranial bleeding) from thrombolysis are also avoided.

A number of retrospective studies have been carried out to determine the impact of primary PTCA on myocardial function and to identify subsets of patients who are most likely to benefit. ${ }^{10,28,30,31}$ In a study involving 250 patients, Kahn $e t a l^{8}$ achieved excellent patency rates in excess of $90 \%$, an in-hospital reocclusion rate of less than $10 \%$ and an acceptable hospital mortality of $5 \%$. Infarct patients ineligible for thrombolytic therapy, and those with left anterior descending coronary artery occlusions who were at highest risk of cardiogenic shock and death, were particularly likely to benefit from primary PTCA. The most impressive results are seen in patients with single vessel disease, when a recanalisation rate of $99 \%$, an in-hospital death rate of $1 \%$ and urgent coronary artery by-pass grafting rate of $<0.5 \%$ can be expected. ${ }^{32}$

Primary PTCA has also been shown to be of great value in patients with previous coronary artery by-pass grafting ${ }^{33}$ and in the elderly, ${ }^{34}$ and can be performed in patients with hypotension and cardiogenic shock. This latter condition, which has an approximate incidence of $10 \%,{ }^{35}$ is associated with a grave prognosis despite thrombolytic therapy due to the low frequency of recanalisation. ${ }^{36}$ Primary PTCA has been found to offer a survival advantage in this group of patients. ${ }^{21,37,38}$ In our limited experience, however, it would seem to offer little to those with established cardiogenic shock, late ( $>6$ hours) after extensive infarction.

\section{Conclusions}

Evidence is now accumulating that, in experienced hands, primary PTCA is the most effective treatment for acute myocardial infarction. ${ }^{7-9}$ However, there remain many questions which need to be answered. Perhaps the most important is whether the clinical advantages of primary PTCA over intravenous therapy are sufficient to justify the huge capital outlay and running costs which would be 
required to provide a 24-hour nationwide service. No less important is whether it should be offered to all patients; should there be an age or time limit, and when, where and who should perform the procedure? Would other interventional devices, in particular intracoronary stents, prove to be of additional value and can we afford to use them? Despite the evidence favouring primary PTCA, there has been little effort to answer these questions. There is currently a lack of enthusiasm for primary PTCA amongst cardiologists, not only because of the spectre of an overwhelming increase in workload - often at extremely unsociable hours, but also because of the lack of staff and facilities to support such a programme. In the UK, a working party is needed to address the medical, social and financial implications of a nationwide service for primary PTCA, otherwise this effective, but logistically complex form of treatment, will continue to be offered only to a select group of patients, and denied to the majority.

1 De Wood MA, Spores J, Notske $\mathrm{R}$, et al. Prevalence of total coronary occlusion during the early hours of transmural myocardial infarction. N Engl $\mathcal{F}$ Med 1980; 303: 897-902.

2 ISIS-2 Collaborative Group. Randomised trial of intravenous streptokinase, oral aspirin, both or neither among 17,187 cases of suspected acute meither among 17,187 cases of suspected acute myocardial

3 Meyer J, Merx W, Dorr R, et al. Sequential intervention procedures after intracoronary thrombolysis; balloon dilatation, bypass surgery and medical treatment. Int $\mathcal{f}$ Cardiol 1985; 7: $281-93$.

4 Grech ED, Ramsdale DR. Percutaneous transluminal coronary angioplasty and acute myocardial infarction. Br $\mathcal{F}$ Hosp Med 1994; 52: 35-41.

5 Hartzler GO, Rutherford BD, McConahay DR, et al. Percutaneous transluminal coronary angioplasty with and without thrombolytic therapy for tast went of acute myocardial inf therapy for Heart $\mathcal{F}$ 1983; 106: 965-73.

6 O'Neill W, Timmis GC, Bourdillon PD, et al. A prospective randomized clinical trial of intracorprospective randomized clinical trial of intracoronary streptokinase versus coronary angioplasty for acute myocardia

7 Zijlstra F, de Boer MJ, Hoorntie JCA, Reiffers S, Reiber JHC, Suryapranata H. A comparison of immediate coronary angioplasty with intravenous streptokinase in acute myocardi infarction. N Engl f Med 1993; 328: 680-4.

8 Grines CL, Browne KF, Marco J, et al. A comparison of immediate angioplasty with thrombolytic therapy for acute myocardia infarction. N Engl f Med 1993; 328: 673-9.

9 Gibbons RJ, Holmes DR, Reeder GS, Bailey $\mathrm{KR}$, Hopfenspirger MR, Gersh BJ. Immediate angioplasty compared with the administration of a thrombolytic agent followed by conservative treatment for myocardial infarction. $N$ Engl $\mathcal{f}$ Med 1993; 328: 685-91.

10 Hartzler GO, Rutherford BD, McConahay DR. Percutaneous transluminal coronary angioplasty: application for acute myocardial infarction. $\mathbf{A m} f$ Cardiol 1984; 53: 117C-121C.

11 Kahn JK, Rutherford BD, McConahay DR, et al. Results of primary angioplasty for acute myocardial infarction in patients with multivesse coronary artery disease. $\mathcal{F}$ Am Coll Cardiol 1990; 16: $1089-96$

12 O'Neill WW, Brodie BR, Ivanhoe $R$, et al. Primary coronary angioplasty for acute myocardial infarction (the primary angioplasty registry). Am $\mathcal{f}$ Cardiol 1994; 73: 627-34.

13 Verstraete $M$, Bernard $R$, Bory $M$, et al. Randomised trial of intravenous recombinant tissue-type plasminof in nous streptokinase in acute myocardial infarction. Lancet 1985; 1: 842-7.
14 Veen G, Meyer A, Verheugt FWA. Culprit lesion morphology and stenosis severity in the prediction of reocclusion after coronary thrombolysis: angiographic results of the APRICOT study. F Am Coll Cardiol 1993; 22: 1755-62

$15 \mathrm{An}$ international randomized trial comparin four thrombolytic strategies for acute myocardial infarction. The GUSTO investigators. $N$ Engl $f$ infarction. The GUSTO

16 The GUSTO angiographic investigators. The effects of tissue plasminogen activator, streptokinase or both on coronary artery patency, ventricular function and survival after acute
myocardial infarction. $N$ Engl $\mathcal{F}$ Med 1993; 329: 1615-22.

17 Colavita PG, Ideker RE, Reimer KA, Hacke DB, Stack RS. The spectrum of pathology associated with percutaneous transluminal coronary angioplasty during acute myocardial infarction. $7 \mathrm{Am}$ Coll Cardiol 1986; 8: 855-60.

18 Mathey DG, Schofer J, Kuck KH, Beil U, Kloppel G. Transmural haemorrhagic myocardial infarction after intracoronary streptokinase. dial infarction after intracoronary streptokinase. Clinical, angiographic and

19 O'Keefe JH, Rutherford BD, McConahay DR Early and late results of coronary angioplasty without antecedent thrombolytic therapy for acute myocardial infarction. Am $\mathcal{F}$ Cardiol 1989; 64: $1221-30$

20 Brodie BR, Weintraub RA, Stuckey TD, et al. Outcomes of direct coronary angioplasty for acute myocardial infarction in candidates and non-candidates for thrombolytic therapy. $A m$ Cardiol 1991; 67: 7-12.

21 Lee L, Erbel R, Brown TM, Laufer N, Meyer J, O'Neill WW. Multicenter registry of antioplasty therapy of cardiogenic shock: initial and longterm survival. $f$ Am Coll Cardiol 1991; 17: 599603.

22 de Boer MJ, Zÿlstra F. Coronary angioplasty in myocardial infarction. In: Grech ED, Ramsdale DR, eds. Practical interventional cardiology. London: Martin Dunitz, 1996; pp 123-140.

23 Brodie BR, Stuckey TD, Hansen CJ, et al. Importance of a patent infarct-related artery for hospital and late survival after direct coronary angioplasty for acute myocardial infarction. $A m \mathcal{F}$ Cardiol 1992; 69: 1113-9.

24 O'Murchu B, Gersh BJ, Reeder GS, Bailey GS, Holmes DR. Late outcome after percutaneous transluminal coronary angioplasty during acute myocardial infarction. Am $\mathcal{F}$ Cardiol 1993; 72: 634-9.

25 Eckleberg T, Vlietstra RE, Brenner AS, Grines CL, O'Neill WW, Browne KF. Cost comparison of primary angioplasty versus thrombolytic therapy for acute myocardial infarction. $\mathcal{F} \mathrm{Am} \mathrm{Coll}$ apy for acute myocardial
Cardiol 1993; 21: 347A.
26 Gacioch GM, Topol EJ. Sudden, paradoxical clinical deterioration during angioplasty of the right coronary artery in acute myocardial infarction. F Am Coll Cardiol 1989; 14: 1202-9.

27 Grech ED, Ramsdale DR. Termination of reperfusion arrhythmias by coronary artery reperfusion arrhythmias by coronary

28 Kahn JK, Rutherford BD, McConahay DR, et al. Catheterization laboratory events and hospita outcome with direct angioplasty for acute myocardial infarction. Circulation 1990; 82 1910-5.

29 Stone GW, Grines CL, Browne KF, et al. Predictors of in-hospital and 6-month outcome after acute myocardial infarction in the reperfusion era, the primary angioplasty in myocardial infarction (PAMI) trial. $\mathcal{F}$ Am Coll Cardiol 1995; 25: $370-7$.

30 Vacek JL, Rosamond TL, Kramer PH, et al. Direct angioplasty versus initial thrombolytic therapy for acute myocardial infarction: longtherapy for acute myocardial infarction: longterm follow-up and changes in pract

31 O'Keefe JH Jr, Rutherford BD, McConahay $\mathrm{DR}$, et al. Myocardial salvage with direct coronary angioplasty for acute infarction. $A m$ Heart F 1992; 123: 1-6.

32 Stone GW, Rutherford BD, McConahay DR, et al. Direct coronary angioplasty in acute myocardial infarction: outcome in patients with single vessel disease. F Am Coll Cardiol 1990; 15: 53443.

33 Kahn JK, Rutherford BD, McConahay DR, et al. Usefulness of angioplasty during acute myocardial infarction in patients with prior coronary artery bypass grafting. Am $f$ Cardiol 1990; 65: 698-702.

34 Lee TC, Laramee LA, Rutherford BD, et al. Emergency percutaneous transluminal coronary angioplasty for acute myocardial infarction in patients 70 years of age and older. $\mathrm{Am} \mathcal{F}$ Cardio 1990; 66: 663-7.

35 Kuhn LA. The treatment of cardiogenic shock Part I. The nature of cardiogenic shock. $\mathrm{Am}$ Heart $f$ 1967; 74: 578-81.

36 Rentrop P, Blanke H, Karsch KR, Kaiser H, Kostering H, Leitz $\mathrm{K}$. Selective intracoronary thrombolysis in acute myocardial infarction and unstable angina pectoris. Circulation 1981; 63: 307-16.

37 Karalis DG, Parris TM. Coronary angioplasty in cardiogenic shock: a bridge to coronary artery surgery. F Invas Cardiol 1989; 1: 231 -7.

38 Hibbard MD, Holmes DR Jr, Bailey KR, Reeder GS, Bresnahan JF, Gersh BJ. Percutaneous transluminal coronary angioplasty in patients with cardiogenic shock. $\mathcal{f} \mathrm{Am}$ Coll Cardiol 1992; 19: $639-46$. 